\title{
Do foreign exchange and equity markets co-move in Latin American region? Detrended cross-correlation approach
}

\author{
Usman Bashir \\ Researcher, School of Management, University of Science and Technology China, No. 96 \\ Jinzhai Road, Anhui, Hefei, 230026, China \\ Email: usman@mail.ustc.edu.cn
}

\author{
Prof. Yugang YU \\ Professor, School of Management, University of Science and Technology China, No. 96 Jinzhai \\ Road, Anhui, Hefei, 230026, China \\ Email: ygyu@ustc.edu.cn \\ Muntazir Hussain \\ Researcher, School of Management, University of Science and Technology China, No. 96 \\ Jinzhai Road, Anhui, Hefei, 230026, China \\ Email: muntazir@mail.ustc.edu.cn
}

\author{
Prof. Gilney F. Zebende \\ Computational Modeling Program - SENAI CIMATEC, Bahia, Brazil \\ Department of Physics - UEFS , Bahia, Brazil \\ Email: gfzebende@hotmail.com
}

\begin{abstract}
:
This paper investigates the dynamics of the relationship between foreign exchange markets and stock markets through time varying co-movements. In this sense, we analyzed the time series monthly of Latin American countries for the period from 1991 to 2015. Furthermore, we apply Granger causality to verify the direction of causality between foreign exchange and stock market and detrended cross-correlation approach $\left(\rho_{D C C A}\right)$ for any co-movements at different time scales. Our empirical results suggest a positive cross correlation between exchange rate and stock price for all Latin American countries. The findings reveal two clear patterns of correlation. First, Brazil and Argentina have positive correlation in both short and long time frames. Second, the remaining countries are negatively correlated in shorter time scale, gradually moving to positive. This paper contributes to the field in three ways. First, we verified the comovements of exchange rate and stock prices that were rarely discussed in previous empirical studies. Second, $\rho_{D C C A}$ coefficient is robust and powerful methodology to measure the cross correlation when dealing with non stationarity of time series. Third, most of the studies employed one or two time scales using co-integration and vector auto regressive approaches. Not much is known about the co-movements at varying time scales between foreign exchange and stock markets. $\rho_{D C C A}$ coefficient facilitates the understanding of its explanatory depth.
\end{abstract}

JEL Classification:G15, C21, C51, F31, F21 
Keywords: Stock prices, exchange rate, coefficient

\section{Introduction:}

Numerous studies have been conducted regarding the dynamic relationship between stock prices and exchange rates. Whether stock price influences or is influenced by the exchange rates is inconclusive in the literature. Various researchers have focused on the relationship between these two because of the predictability of their influence on one another (Nieh and Lee 2002). These variables have more important implications for the emerging stock markets that are sensitive to exchange rate policies (Abdalla and Murinde 1997). Our focus in this paper is to study the effect of these variables on each other in the Latin American market conditions, mainly in Brazil, Chile, Mexico, and Argentina. Recently, changes in international regulations and elimination of capital inflow hindrances, currency exchange limitations, and adoption of floating exchange rates in foreign exchange and stock markets have become more interdependent (Aydemir and Demirhan 2009).

The two most relevant theories regarding this scenario are the traditional and portfolio balanced approaches. The traditional approach suggests that exchange rate affects stock prices. According to this approach, the exchange rate appreciation (depreciation) affects the firm via the balance sheet and income statement items. It increases (decreases) the overall value of firm, resulting in the equity prices. The second approach is portfolio balanced approach, which refers to the effect of stock prices on the exchange rate. The rise in stock prices tend to attract foreign investors, leading to an increase in foreign capital inflow and creating demand for the local currency, and consequently, the local currency appreciates and vice versa (Tabak 2006).

Empirical literature related to these approaches starts with the study of (Franck and Young 1972). They argued no relationship exists between exchange rate and stock prices. Instead, they supported the asset market approach and negated the traditional and portfolio balance approaches. Thereafter, (Agarwal 1981) tested the relationship between the exchange rate and stock prices, and found that exchange rate affects the stock prices supporting the traditional approach. Several studies (Akumbu 2007, Bahmani-Oskooee and Sohrabian 1992, Dornbusch 1975, Koulakiotis, Kiohos and Babalos 2015) support the portfolio balanced approach. Agarwal (1981), Joseph (2002), Ma and Kao (1990) were inclined toward the traditional approach. Although the reported results of many studies contradict these two approaches and are inclined toward the asset market approach, these results are echoed in the studies of (Franck and Young 1972, Nieh and Lee 2002, Ong, Clements and Izan 1999, Ratner 1993). The direction of the causality differs in different market conditions and might be at different time scales, forcing us to accept one and negate the other explanation. Our question is that do these two markets co-move? To the best of our knowledge, very little is discussed in the literature regarding the co-movement of these markets.

Researchers employ different approaches and methodologies in the literature while delineating the relationship between stock returns and foreign exchange rate movements such as Granger 
causality, cointegration, error correction mechanism, and linear regression (Ajayi and Mougoue 1996, Akumbu 2007, Ding 2009, Koulakiotis, Kiohos and Babalos 2015, Ratner 1993). Most of the literature use the Engel Granger cointegration to find the possible linkages between these variables. This procedure has its own limits. If both markets are asymmetric, using Engel Granger methodology can lead toward biased results by accepting the null hypothesis of no cointegration (Enders and Siklos 2001). Traditional models do not capture the co-movements between these two markets because they only accommodate one or two time scales to interpret in terms of short or long run. In this paper, we attempt to provide a new perspective $\beta_{D O 4}$ the ambiguous relationship by employing the detrended cross-correlation coefficient as developed by (Zebende 2011), across different time scales for non-stationary time series. This methodology is novel in the context that the generation of cross correlation coefficients at different time scales can be helpful to understand this dilemma, because the investor behavior in these two markets can be different with respect to their different investment horizons, leading to foreign exchange and stock market co-movements at different time scales. (Reboredo, RiveraCastro and Zebende 2014) use the detrended cross correlation coefficients to study the oil and exchange rate nexus.

In this paper, we hypothesize that depending on the market condition, portfolio balanced approach does not always exist. Foreign capital can impose upward or downward pressure on the exchange rate. For instance, if the stock market is not fragile in context of volatility, then it could limit the effect of foreign capital on the exchange rate. Although seizing an opportunity for profit, the injection of foreign capital or its flight has a considerable influence on the exchange rate. Using the data on Latin American major economies, we want to investigate the dynamics of the relationship between stock price indexes and foreign exchange rates Rnder different market conditions. To understand the volatility in these relationships, we apply at different time scales to determine whether (a) co-movements exist in these markets, (b) these markets are positively or negatively correlated, (c) these relationships change on varying time scale.

Our study focuses on four markets in Latin America because the major portion of the Latin American economy depends on these four countries, namely, Brazil, Chile, Argentina, and Mexico with respect to GDP (Gross Domestic Product). Since 1980 to 1990, these economies were the major beneficiaries of capital flows in context of portfolio investments. Except for the 1994 currency crisis of Mexico, these economies became more open to the foreign direct investment, capital liberalization, and privatization process, resulting in the enormous growths in exports and the Latin American economy (Bekaert and Harvey 2000, Bekaert, Harvey and Lundblad 2006, Grilli 2005, Salvatore 2001). Our study is relevant to the essential policy implications in context to exchange rate, capital liberalization, and monetary policies in Latin America as an emerging market. To understand the dynamics of the relationship between foreign exchange and stock markets is pivotal for the multinational organizations and investors in this region to enable them to equip and hedge against adverse movements in foreign exchange.

This article is organized into sections. Section 2 provides some empirical studies on the linkages between foreign exchange rates and stock prices. Section 3 provides the data, methodology, and some preliminary descriptive information of our variables. Section 4 discusses the findings and empirical results, and Section 5 concludes the paper. 


\section{2) Literature Review:}

Two main theories relate to the linkages between the foreign exchange rates and equity prices. Dornbusch and Fischer (1980) provide the traditional approach based on the flow-oriented model, suggesting the direction of causality from exchange rate to equity prices. If the exchange rate is competitive, then it will position the economy to be more effective in the context of trade and boost the economy through increasing profitability and prices of firms and equity. The depreciation of local currency will increase the cost of production of local firms who use imported inputs, and consequently will decrease the overall profitability, firm value, and the share prices. The linkage between exchange rate and equity prices can move in both directions. Branson (1981) and Frankel (1987) introduce the stock oriented model based on the portfolio approach, and provide the opposite explanation of the flow approach. A bullish trend in the local stock markets tends to attract foreign capital inflow to increase the economic activity, leading to an appreciation in the foreign exchange rate.

The empirical literature on the linkages between foreign exchange and stock prices has mixed results. (Franck and Young 1972) argued no relationship exists between exchange rate and stock prices. They supported the asset market approach and negated the traditional and portfolio balance approaches by analyzing the exchange rate of six different countries. Agarwal (1981) tested the relationship between the exchange rate and stock prices using the sample period from 1974 to 1978 and employed a simple regression analysis, resulting in positive correlation between stock price indices and exchange rate. He found that the changes in the exchange rate affect the profitability of the multinational firms by modifying the balance sheet items listed in foreign currency, affecting the share price of the firm and the stock market. He supported the traditional approach.

Many studies have been conducted in the developed economies to explore the interdependencies between the foreign exchange and stock price markets, and no relationships were found. For instance, (Ratner 1993) investigated the relationship between US Dollar exchange rate and the US stock prices using cointegration approach. He could not reject the null hypothesis of no cointegration, and hence supported the asset market approach. Similarly, (Ajayi and Mougoue 1996) found no significant relationship between these two markets while studying the developed economies consisting of Canada, Germany, France, Japan, Italy, and Netherland, adopting the error correction mechanism. Nieh and Lee (2002) adopted the Engel-Granger and Johansen cointegration approach while studying the relationship of stock prices and foreign exchange market of G-7 countries; they supported the asset market approach. Ong, Clements and Izan (1999) studied the interdependence between exchange rate and US stock market indices using the non-linear regression approach. He suggested a weak dependence between these two, leading to an increase in currency, and consequently decreases stock market returns. Pan, Fok and Liu (2007) examined the linkages between stock markets and foreign exchange markets of East Asian countries using the Granger causality and VAR approached for the sample period from 1988 to 1998. Their findings supported the traditional approach except for the duration of Asian financial crisis in 1997. Furthermore, the linkages vary across economies in the context of capital flow restrictions, exchange rate regimes, and stock market size. Koulakiotis, Kiohos and Babalos (2015) examined the interaction between stock prices and exchange rate using an asymmetric 
threshold approach for USA, Canada, and United Kingdom, documenting a strong causal relationship between stock market and foreign exchange rate market.

As a developing economy and emerging market, different studies have been conducted on the Latin American market. (Phylaktis and Ravazzolo 2005) used the multivariate Granger causality and cointegration techniques to explore the Pacific Basin region. By using different sample periods from 1980 to 1998 for different countries, a positive relationship was found between stock market and foreign exchange market. They found the US stock market acted as a transmission channel for these markets linkages. Similarly, (Diamandis and Drakos 2011) studied the long and short run relationships between exchange rates and stock prices and the channels through which these markets were affected using US stock market as an exogenous shock to the system. They used a sample period from 1980 to 2009 for four Latin American countries, employing the cointegration and multivariate Granger causality approach. Their results showed a positive relationship between stock markets and foreign exchange markets using the US stock market as a transmission channel for such relationship. Kabir, Bashar and Masih (2014) used the US stock market S\&P 500, NYSE index as a proxy for the global economic condition to study the relationship between foreign exchange rate and Malaysian stock market. The results suggested that the exchange rate influenced the stock prices.

The literature regarding the dynamics of foreign exchange and stock market presented mixed results. The literature regarding this relationship can be categorized into three major categories. Some studies present that the foreign exchange market influences the stock market, whereas the second group of studies conclude that the stock market significantly affects the foreign exchange market. Finally, the third group concludes no relationship. Past studies used different econometric model like ordinary least square method, vector autoregressive method, vector error correction model, co-integration model, impulse response model, generalized method of movements, autoregressive conditional heteroscedasticity family model, and dynamic conditional correlation. Recent studies used the dynamic conditional correlation model, but encountered the data unit root problem (Reboredo, Rivera-Castro and Zebende 2014). In addition to that most of the financial time series data encounter the issue of non statiBirefity, leading to spurious results to handle such problems many research scholars have used on different data sets and considered it a robust methodology in tackling this issue. (e.g. Gu and Zhou 2010, Gvozdanovic, Podobnik, Wang and Stanley 2012, Horvatic, Stanley and Podobnik 2011, Jiang and Zhou 2011, Podobnik, Grosse, Horvatić, Ilic, Ivanov and Stanley 2009, Podobnik, Horvatic, Petersen and Stanley 2009, Zhou 2008). To the best of our knowledge, few studies employ

as developed by (Zebende 2011) to analyze the linkages between foreign exchange and stock market especially in the case of Latin American countries.

\section{Hypothesis}

We have to ascertain these pivotal issues based on international finance theories. (a) Does the exchange rate influence stock price? (b) Does stock prices influence the exchange rate? (c) Does bi-directional causality exists between stock price and exchange rate? (d) Do exchange rate and stock prices co-move? The following are the null hypotheses for possible rejection. 
(a) H0: Exchange rate does not influence the stock price.

(b) H0: stock price does not influence the exchange rate.

(c) H0: Bi-directional causality does not exist between exchange rate and stock price.

(d) H0: Co-movement does not exist between exchange rate and stock price.

\section{3) Methodology and Data:}

We employ to analyze the co-movements between foreign exchange and stock markets following the methodology of (Zebende 2011). We use Granger causality to identify the direction of causality to determine which of the two markets can predict the other.

\subsection{DCCA}

To conduct an in-depth analysis on the dynamics of relationship between foreign exchange and stock market at varying time scales, we adopt the methodology proposed by (Zebende 2011), which is based on DCCA of (Podobnik and Stanley 2008). This method is a generalization of the detrended fluctuation analysis (DFA) proposed by (Peng, Buldyrev, Havlin, Simons, Stanley and Goldberger 1994) it is based on the power law cross correlations. The method provides the value of coefficient $\alpha$, which is the long-range auto-correlation scaling exponent. The values for alphas are interpreted as $\alpha=0.5$, implying no auto-correlation, if $\alpha<0.5$ and $\alpha>0.5$, leading to anti-persistent and a persistent auto-correlations in the series. Most of thedfigtancial time series data encounter the issue of non stationarity, leading to spurious results. deals with such non stationary issue, and hencest the approach is more robust than the linear models in non stationary time series data. $\quad(n)$ is calculated by using DCCA and DFA methods for any two time series such as $\left\{X_{t}\right\}$ and $\left\{Y_{t}\right\}\left\{\mathrm{X}_{\mathrm{t}}\right\}$ and $\left\{\mathrm{Y}_{\mathrm{t}}\right\}$ with same size $T$, and in our case, the foreign exchange rate $\left\{X_{t}\right\}$ and stock returns $\left\{Y_{t}\right\}$. The process is expressed as

$\rho_{D C C A}(n)=\frac{F_{D C C A}^{2}(n)}{F_{D F A \cdot x}(n) F_{D F A \cdot y}(n)}$

where $F_{D C C A}^{2}(n)$ is the detrended covariance function, by DCCA method, and $F_{D F A \cdot x}(n)$ and $F_{D F A \cdot y}(n)$ are the root-mean-square fluctuation, by DFA method. Where $n$ is the window size.

Then, these fluctuations are entered into equation (3.1). (Podobnik, Jiang, Zhou and Stanley 2011) show that $-1<\rho_{D C C A}(n)<1$, such that DCCA coefficient can be interpreted as a standard correlation coefficient with $\rho_{D C C A}(n)=-1$ for highly negative cross-correlated series, $\rho_{D C C A}(n)=1$ for highly positive cross-correlation in the series, and $\rho_{D C C A}(n)=0$ for no cross- 
correlation between the series. (For details, see Zebende, 2011 and for empirical results see (Reboredo, Rivera-Castro and Zebende 2014).

\subsection{Granger Causality Test}

We apply the Granger causality test to check the direction of causation between foreign exchange and stock markets. The stock markets influence the foreign exchange market or vice versa. The equation specification for this test is as follows: suppose we have two variables $E X$ and $S I$, which represent the foreign exchange market and stock market. The equation to verify the direction of causation is expressed as

$$
E X_{t}=\gamma_{0}+\gamma_{1} E X_{t-1}+\cdots+\gamma_{p} E X_{t-p}+\varphi_{1} S I_{t-1}+\cdots+\varphi_{p} S I_{t-p}+\mu_{t}
$$

Two tests are run at the same time to verify the direction of causation from both sides. The second equation is expressed as

$$
S I_{t}=\gamma_{0}+\gamma_{1} S I_{t-1}+\cdots+\gamma_{p} S I_{t-p}+\varphi_{1} E X_{t-1}+\cdots+\varphi_{p} E X_{t-p}+\mu_{t}
$$

The null hypotheses for both equations (3.2) and (3.3) are rejected if the coefficients $\varphi$ values in the above two equations are zero simultaneously, and will be interpreted as stock markets predict the exchange rate markets for equation (3.2) and vice versa for equation (3.3).

\subsection{Data}

We use four Latin American countries, namely, Brazil, Mexico, Chile, and Argentina for our analysis. These data are based on the stock indices and the exchange rate is in terms of US dollars monthly from 1991 to 2015. Specifically, the data for Brazil ranging from April 1993 to February 2015, Mexico from November 1991 to February 2015, Chile from October 1996 to February 2015, and Argentina from October 1993 to February 2015. This is because of data availability issue. Data are extracted from Yahoo Finance and International Financial Statistics data base (IFS-CD) maintained by the IMF website.

\section{\{Insert Figure 1 here\}}



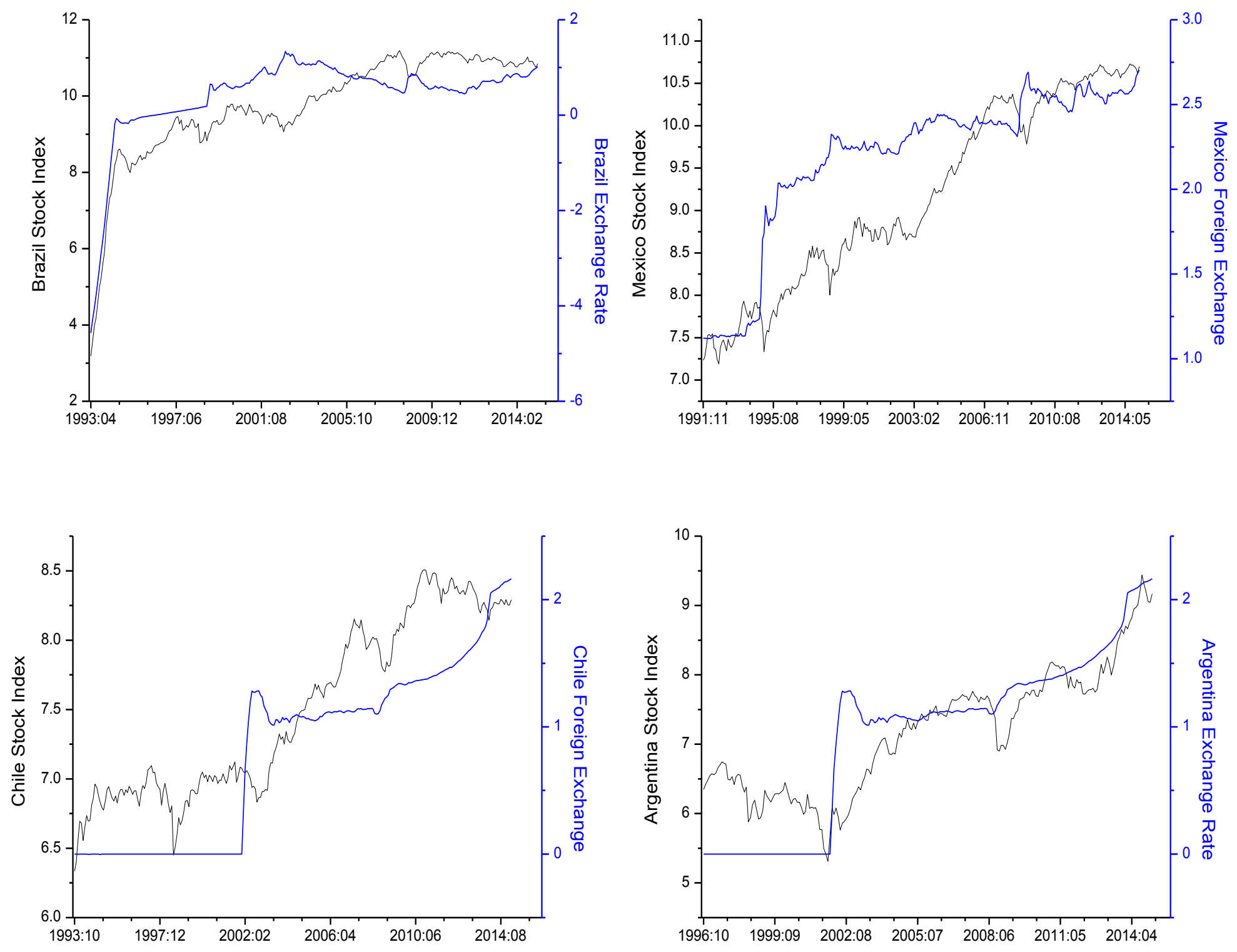

Figure 1: Exchange rate and stock market index of Latin American countries from periods of 1991 to 2015. Data index are in $\log$ scale.

We put the data in logarithmic form. Estimating separate system of equations for all the four countries enables us to use the different data ranges for the four Latin American countries.

Figure 1 represents the stock index and exchange rate dynamics for our Latin American countries from 1991 to 2015. The stock index and the exchange markets move in the opposite direction for 
almost all the countries throughout the sample period. For Brazil and Mexico, the co-movements are more intense than the other two Latin American countries. The descriptive statistics of both markets for our Latin American countries are given in Table 3.1. Mexico has the highest mean return values for the foreign exchange market, whereas Brazil has the lowest. Brazil has the highest mean return value for stock market, whereas Argentina has the lowest value. The standard deviation value for Brazil exchange rate is higher than its other Latin American counterparts because of a more volatile currency. The standard deviation values for stock markets depict that Brazil and Mexico are more volatile than Chile and Mexico. Both the foreign exchange and stock markets are negatively skewed with the exception of Chile and Argentina stock markets.

Table 3.1. Descriptive Statistics of Foreign Exchange and Stock Market for our Latin American Countries between 1991 to 2015.

\begin{tabular}{lccccccc}
\hline & Mean & Std. Dev. & Sk & Kurt & Jar-Be & ARCH-LM & Obs \\
\hline Brazil-Ex & 0.428 & 0.868 & -3.539 & 17.430 & $0.000^{* * *}$ & $0.000^{* * * *}$ & 263 \\
Brazil-Si & 9.774 & 1.383 & -1.988 & 8.642 & $0.000^{* * * *}$ & $0.000^{* * * *}$ & 263 \\
Mexico-Ex & 2.187 & 0.450 & -1.463 & 3.950 & $0.000^{* * * *}$ & $0.000^{* * * *}$ & 280 \\
Mexico-Si & 9.178 & 1.103 & -0.077 & 1.626 & $0.000^{* * *}$ & $0.000^{* * * *}$ & 280 \\
Chile-Ex & 0.813 & 0.693 & -0.027 & 1.651 & $0.000^{* * *}$ & 0.855 & 257 \\
Chile-Si & 7.501 & 0.625 & 0.186 & 1.494 & $0.000^{* * *}$ & $0.000^{* * * *}$ & 257 \\
Argentina-Ex & 0.945 & 0.657 & -0.341 & 2.011 & $0.001 * * *$ & 0.841 & 221 \\
Argentina-Si & 7.173 & 0.891 & 0.228 & 2.387 & $0.068^{*}$ & $0.000^{* * * *}$ & 221 \\
\hline
\end{tabular}

Note: Monthly data for Brazil 04/1993-02/2015, Mexico 11/1991-02/2015, Argentina 10/1996-02/2015 and Chile $10 / 1993-02 / 2015$ for stock Indices and exchange rate in terms of USD, Ex is the exchange rate time series and Si is the stock index for respective country. The table presents basic statistics for the time series mean, standard deviation (std dev), skewness (sk), kurtosis (kurt). Jar-Be is the Jarque Bera test for the normality of the time series based on the kurtosis and skewness of the data probability values. ARCH-LM is the autoregressive conditional heteroscedasticity test based on Lagrange Multiplier. Obs are the number of monthly observations for each market used in analysis. *,**, and *** refer to the p-values for the respective test rejecting the null hypothesis significant at $0.10,0.05$, and 0.01 levels, respectively.

The higher value of kurtosis is from Brazil (Kurt $>3$ means that data has platykurtic properties). The Jarque Bera statistics rejects the null hypothesis of all the series being normally distributed. The Lagrange multiplier test for autoregressive conditional heteroscedasticity confirmed the presence of $\mathrm{ARCH}$ effect in the time series data for all the return series with the exception of Argentina Stock market.

\section{4) Results:}

The result for Granger causality between the foreign exchange and stock market is given in Table 4.1. We estimated the results at two lags and found mixed results. In most cases, the foreign exchange market influences the stock market, except for Chile. We were unable to accept the null hypothesis for Mexico and Argentina stock markets, resulting in the conclusion that 
these two markets have certain interdependencies, which might change because of different market conditions. In the case of Brazil foreign exchange rate influencing the stock index, hence supporting the traditional approach. Mexico and Argentina have bidirectional causality supporting traditional and portfolio balanced approaches as that of Chile, support the asset market approach. As for Mexico and Argentina, both markets are influencing each other, leading to a conclusion that these two markets might influence each other at different time scales differently.

Table 4.1.Granger Causality Test of Foreign Exchange and Stock Market for our Latin American Countries since 1991 to 2015.

\begin{tabular}{lcll}
\hline H0 : Foreign exchange does not cause stock index & Lag & F-statistics & Result H0 \\
\hline Brazil foreign exchange and Stock Index & 2 & $\begin{array}{l}14.6227 \\
(0.001)^{* * *}\end{array}$ & Rejection of H0 \\
Mexico foreign exchange and stock index & 2 & $\begin{array}{l}6.93609 \\
(0.001)^{* * *}\end{array}$ & Rejection of H0 \\
Chile foreign exchange and stock index & 2 & $\begin{array}{l}2.6288 \\
(0.074)^{* *}\end{array}$ & Acceptance of H0 \\
Argentina foreign exchange and stock index & 2 & $\begin{array}{l}6.3206 \\
(0.002)^{* * *}\end{array}$ & Rejection of H0 \\
\hline H0 : Stock Index does not cause foreign exchange & & & \\
\hline Brazil Stock index and foreign exchange & 2 & $\begin{array}{l}1.46411 \\
(0.233)\end{array}$ & Acceptance of H0 \\
Mexico Stock index and foreign exchange & 2 & $\begin{array}{l}23.4341 \\
(0.000)^{* * *}\end{array}$ & Rejection of H0 \\
Chile Stock index and foreign exchange & 2 & $\begin{array}{l}2.2496 \\
(0.108)\end{array}$ & Acceptance of H0 \\
Argentina Stock index and foreign exchange & 2 & $\begin{array}{l}6.83326 \\
(0.001)^{* * *}\end{array}$ & Rejection of H0 \\
\hline
\end{tabular}

Note: H0 is the null hypothesis for both equations (3.2) and (3.3), estimated to check the direction of causality for foreign exchange and stock index for four Latin American countries for the following periods of Brazil 04/199302/2015, Mexico 11/1991-02/2015, Argentina 10/1996-02/2015 and Chile 10/1993-02/2015. F-statistics values are given with respective p-values clustered in parenthesis. *, **, and $* * *$ are the levels of significance at $1 \%, 5 \%$, and $10 \%$, respectively, for rejecting or accepting the null hypothesis.

Next to understand the co-movements between foreign exchange and stock market, we apply the DCCA cross-correlation coefficient to examine the stock market and exchange rate time sefiescin our Latin American countries. Thus, we estimated the cross correlation coefficients which are given in Figure 2, showing the cross-correlation results for both Rafkets over different time scales. The diamond in Figure 2 represents the DCCA coefficients for each of the four Latin American countries.

\section{\{Insert Figure 2 here\}}



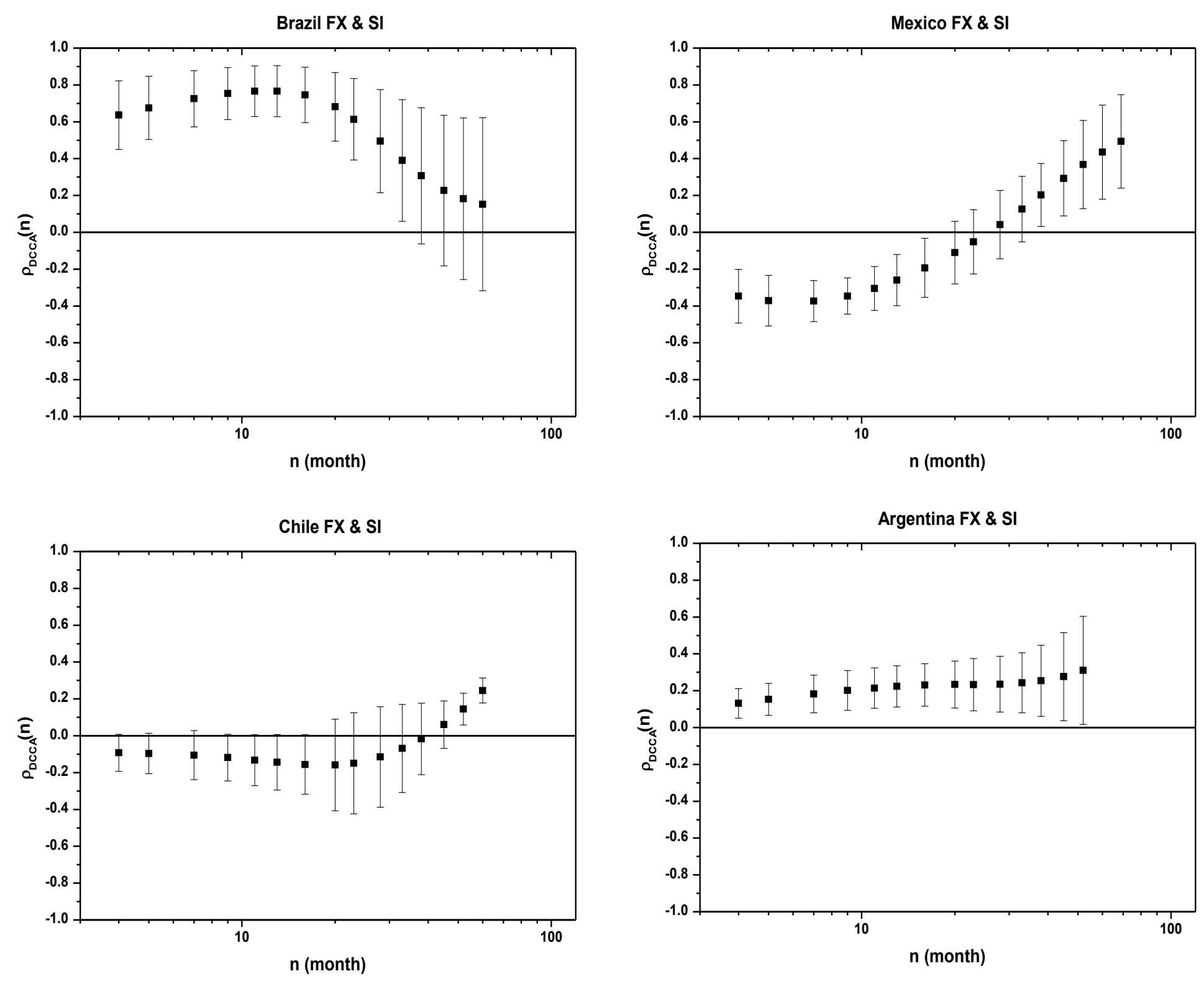

Figure 2: Foreign exchange and stock index coefficients calculated by the detrended cross-correlation coefficient. Vertical lines in data represents the standard deviation.

We found sBmpesinteresting results for all the countries in the sample. The cross correlation coefficient is positive in the long run with correlations at almost 0.2 or higher. Interdependence exists between these two markets. We found two patterns of results. First is the strong positive correlation for shorter time scales, which decreases in the long run or remains consistent. The second pattern is the negative correlation for shopten time scales, which decreases and becomes positive over longer time scales. If we examine cross correlation coefficient 
for Brazil individually, it has a strong positive correlation between both markets, which strengthens for shorter time scale for 10 months at almost 0.8 , but in the long run, the correlation remains positive although weak compared to the shorter time scale and decreases after the 10th month and becomes 0.2. Similarly, the correlation in terms of co-movement is weak in Argentina compared to Brazil. The small-scale correlation is positive but weak and near zero. However, for longer time scales, the correlation increases and reaches 0.3. Mexico and Chile behave differently. Mexico has weak negative correlation of 0.3 at the start for shorter time scale, which further diminishes and becomes positive during longer time scales and reaches the value of 0.5 , with a strong positive correlation. For Chile, $Q_{\text {dke }}$ pattern of co-movement is similar to Mexico, but less in magnitude with respect to the correlation coefficient values. The value for correlation is weak and negative, which increases as it moves toward longer time scale and becomes positive at the end of the time scale, nearly reaching the value of 0.3 .

\section{Discussion and Policy Implications}

Our study is relevant to the essential policy implications in the contexts of exchange rate, capital liberalization, and monetary policies with respect to Latin America as an emerging market. To understand the dynamics of relationship between foreign exchange and stock markets is pivotal for the multinational organizations and investors working in this region. To equip and hedge themselves against adverse movements in foreign exchange. The positive (negative or null) cross-correlation between exchange rate and stock prices can be healthy sign for import-oriented companies because of the reduction in operating, production, and administrative costs. Their revenues will improve, but the reduction could adversely affect a company engaged in exportoriented activities. Exports will be more expensive than imports for international countries if the exchange rate appreciates Exchange rate appreciation would increase export revenue for domestic firms in the short run (e.g., pending/open export contracts), but adversely in the long run. The findings have implications for the central banks of Latin American countries included in our sample. Second, the financial stability in Latin American countries will be affected by the fluctuations in the exchange rate. The monitoring policy officials should be aware of such shocks as fluctuation in exchange rate can have diverse effect on prices through exchange rate pass through mechanism. Finally, Latin American countries should consider stock price and exchange rate links while devising policies for capital budgeting, investment, and risk management strategies in view of the international scenario depending on the domestic market situation.

\section{Conclusion}

We explore the relationship between exchange rate and stock prices for four Latin American countries, Brazil, Mexico, Chile, and Argentina. We used monthly time series ranging from 1991 to 2015 and we apply the DCCA method. We found some interesting results for these Latin American countries. For most of the countries, we found weak positive cross-correlation for exchange rate and stock prices except for Mexico, which has a strong positive cross-correlation coefficient $\square 0.5$ for longer time scale and a minimum value of correlation $\square 0.2$ for Brazil. In our study, we found two patterns based on varying time scales for all the countries in our sample. For Brazil and Argentina, we found almost similar patterns, but with higher magnitude for Brazil in which the correlation is strongly positive for shorter time scales, and reducing in the long run. Although Argentina has a weak positive correlation, with slight and sluggish increase in longer 
periods. The second pattern refers to Mexico and Chile, which is similar to each other because of the negative correlation in the shorter time frame, and the correlation becomes positive in the long run. Mexico has strong positive correlation value of 0.5 in the longer time frame as compared to Chile, which has a weak positive correlation.

This study is significant for the policy implications in relation to central bank monetary and fiscal policies in the context of Latin American emerging economies. Multinational, domestic organizations, portfolio managers, and investors working in this region must be aware of the dynamic linkages between the exchange rate and stock prices to avoid any risk and hedge themselves against volatile market conditions.

\section{References}

Abdalla, Issam SA and Victor Murinde (1997), 'Exchange rate and stock price interactions in emerging financial markets: evidence on India, Korea, Pakistan and the Philippines', Applied financial economics, 25-35.

Agarwal, R (1981), 'Exchange Rate and Stock Prices: A Study of US Capital Markets under Floating Exchange Rate', Akron Business and Economics Review, 7-12.

Ajayi, Richard A and Mbodja Mougoue (1996), 'On the dynamic relation between stock prices and exchange rates', Journal of Financial Research, 193-207.

Akumbu, Nshom Martin (2007), 'The association of Exchange rates and Stock returns: Linear Regression analysis'.

Aydemir, Oguzhan and Erdal Demirhan (2009), 'The relationship between stock prices and exchange rates evidence from Turkey', International Research Journal of Finance and Economics, 207-15.

Bahmani-Oskooee, Mohsen and Ahmad Sohrabian (1992), 'Stock prices and the effective exchange rate of the dollar', Applied economics, 459-64.

Bekaert, Geert and Campbell R Harvey (2000), 'Foreign speculators and emerging equity markets', The Journal of Finance, 565-613.

Bekaert, Geert, Campbell R Harvey and Christian Lundblad (2006), 'Growth volatility and financial liberalization', Journal of international Money and Finance, 370-403.

Branson, William H (1981), 'Macroeconomic determinants of real exchange rates': National Bureau of Economic Research Cambridge, Mass., USA.

Diamandis, Panayiotis F and Anastassios A Drakos (2011), 'Financial liberalization, exchange rates and stock prices: Exogenous shocks in four Latin America countries', Journal of Policy Modeling, 381-94.

Ding, Liang (2009), 'Bid-ask spread and order size in the foreign exchange market: an empirical investigation', International Journal of Finance \& Economics, 98-105.

Dornbusch, Rudiger (1975), 'A portfolio balance model of the open economy', Journal of Monetary Economics, 3-20.

Dornbusch, Rudiger and Stanley Fischer (1980), 'Exchange rates and the current account', The American Economic Review, 960-71. 
Enders, Walter and Pierre L Siklos (2001), 'Cointegration and threshold adjustment', Journal of Business \& Economic Statistics, 166-76.

Franck, Peter and Allan Young (1972), 'Stock price reaction of multinational firms to exchange realignments', Financial Management, 66-73.

Frankel, Jeffrey A (1987), Monetary and portfolio-balance models of exchange rate determination. University of California, Berkeley, Department of Economics.

Grilli, Enzo (2005), 'Political economy and economic development in Latin America in the second half of the 20th century', Journal of Policy Modeling, 1-31.

$\mathrm{Gu}$, Gao-Feng and Wei-Xing Zhou (2010), 'Detrending moving average algorithm for multifractals', Physical Review E, 011136.

Gvozdanovic, Igor, Boris Podobnik, Duan Wang and H Eugene Stanley (2012), '1/f behavior in cross-correlations between absolute returns in a US market', Physica A: Statistical Mechanics and its Applications, 2860-6.

Horvatic, Davor, H Eugene Stanley and Boris Podobnik (2011), 'Detrended cross-correlation analysis for non-stationary time series with periodic trends', EPL (Europhysics Letters), 18007.

Jiang, Zhi-Qiang and Wei-Xing Zhou (2011), 'Multifractal detrending moving-average crosscorrelation analysis', Physical Review E, 016106.

Joseph, Nathan L (2002), 'Modelling the impacts of interest rate and exchange rate changes on UK stock returns', Derivatives Use, Trading and Regulation, 306-23.

Kabir, Sarkar Humayun, Omar KMR Bashar and A Mansur M Masih (2014), 'Is Domestic Stock Price Cointegrated with Exchange Rate and Foreign Stock Price?: Evidence from Malaysia', The Journal of Developing Areas, 285-302.

Koulakiotis, Athanasios, Apostolis Kiohos and Vassilios Babalos (2015), 'Exploring the interaction between stock price index and exchange rates: an asymmetric threshold approach', Applied economics, 1-13.

Ma, Christopher K and G Wenchi Kao (1990), 'On exchange rate changes and stock price reactions', Journal of Business Finance \& Accounting, 441-9.

Nieh, Chien-Chung and Cheng-Few Lee (2002), 'Dynamic relationship between stock prices and exchange rates for G-7 countries', The Quarterly Review of Economics and Finance, 477-90.

Ong, Li Lian, Kenneth W Clements and HY Izan (1999), 'The world real interest rate: stochastic index number perspectives', Journal of international Money and Finance, 225-49.

Pan, Ming-Shiun, Robert Chi-Wing Fok and Y Angela Liu (2007), 'Dynamic linkages between exchange rates and stock prices: Evidence from East Asian markets', International Review of Economics \& Finance, 503-20.

Peng, C-K, Sergey V Buldyrev, Shlomo Havlin, Michael Simons, H Eugene Stanley and Ary L Goldberger (1994), 'Mosaic organization of DNA nucleotides', Physical Review E, 1685.

Phylaktis, Kate and Fabiola Ravazzolo (2005), 'Stock prices and exchange rate dynamics', Journal of international Money and Finance, 1031-53.

Podobnik, Boris, Ivo Grosse, Davor Horvatić, S Ilic, P Ch Ivanov and H Eugene Stanley (2009), 'Quantifying cross-correlations using local and global detrending approaches', The European Physical Journal B, 243-50.

Podobnik, Boris, Davor Horvatic, Alexander M Petersen and H Eugene Stanley (2009), 'Crosscorrelations between volume change and price change', Proceedings of the National Academy of Sciences, 22079-84.

Podobnik, Boris, Zhi-Qiang Jiang, Wei-Xing Zhou and H Eugene Stanley (2011), 'Statistical tests for power-law cross-correlated processes', Physical Review E, 066118. 
Podobnik, Boris and H Eugene Stanley (2008), 'Detrended cross-correlation analysis: a new method for analyzing two nonstationary time series', Physical review letters, 084102.

Ratner, Mitchell (1993), 'A cointegration test of the impact of foreign exchange rates on US stock market prices', Global Finance Journal, 93-101.

Reboredo, Juan Carlos, Miguel A Rivera-Castro and Gilney F Zebende (2014), 'Oil and US dollar exchange rate dependence: A detrended cross-correlation approach', Energy Economics, 132-9.

Salvatore, Dominick (2001), 'Which countries in the Americas should dollarize?', Journal of Policy Modeling, 347-55.

Tabak, Benjamin M (2006), 'The dynamic relationship between stock prices and exchange rates: Evidence for Brazil', International Journal of Theoretical and Applied Finance, 1377-96.

Zebende, GF (2011), 'DCCA cross-correlation coefficient: quantifying level of cross-correlation', Physica A: Statistical Mechanics and its Applications, 614-8.

Zhou, Wei-Xing (2008), 'Multifractal detrended cross-correlation analysis for two nonstationary signals', Physical Review E, 066211. 